\title{
Moralidade e homicídio: um estudo sobre a ação do transgressor ${ }^{1}$
}

\author{
Luciana Souza Borges ${ }^{2}$ \\ Heloisa Moulin de Alencar \\ Universidade Federal do Espirito Santo, Vitória-ES, Brasil
}

\begin{abstract}
Resumo: Investigamos juízos de representação da realidade e valor moral de 20 homens homicidas, com idade variando entre 30 e 49 anos, sobre a ação transgressora acerca do passado e do presente. Realizamos entrevistas individuais, pelo método clínico piagetiano, e verificamos que: o JRR (juízo de representação da realidade) mais citado no passado foi o de que cometeriam novamente o homicídio, pela humilhação sofrida ou pelo sentimento negativo experienciado; no presente mencionaram que não matariam de novo, devido às consequências negativas do crime, às características próprias ou da vítima e ao valor da vida; o JVM (juízo de valor moral) mais mencionado no passado foi o de que a ação seria errada, pelas consequências negativas; no presente todos julgaram como errado o homicídio cometido, devido às consequências negativas, ao valor atribuído à vida e a motivos religiosos. Esperamos que essas discussões possibilitem maior compreensão do sujeito homicida, para que princípios universais, como o respeito à vida, possam ser considerados e ensinados.
\end{abstract}

Palavras-chave: moral, transgressão, homicídio.

\section{Morality and homicide: a study about the transgressor's action}

\begin{abstract}
We investigated the judgments of representation of reality (JRR) and judgment of moral value (JMV) about transgressing actions, concerning the past and present time, of 20 homicidal men aged between 30 and 49 years. Individual interviews using the clinical piagetian method were carried out and the following were verified: the most cited JRR in the past was the one that they would commit the homicide again, due the suffered humiliation or the experienced negative feeling; in the present they reported they would not kill again due to the crime negative consequences, to their own or the victim's characteristics and life's value; the JMV most mentioned in the past was the one that the action would be wrong due the negative consequences; in the present all of them considered wrong the committed homicides due to the negative consequences, value attributed to life and religious reasons. We expect that this discussion permit a deeper understanding of the homicidal individual so that universal principles such as respect for life can be taught and taken into consideration.
\end{abstract}

Keywords: morality, transgression, homicide.

\section{Moralidad y homicidio: un estudio sobre la acción del transgresor}

Resumen: Investigamos juicios de representación de la realidad y valor moral de 20 hombres homicidas, con edades entre 30 y 49 años, sobre la acción transgresora, acerca del pasado y del presente. Realizamos entrevistas individuales, por el método clínico piagetiano, y verificamos que: el JRR (juicios de representación de la realidad) más citado en el pasado fue que cometerían nuevamente el homicidio, por la humillación sufrida o por el sentimiento negativo experimentado; en el presente mencionaron que no matarían nuevamente, debido a las consecuencias negativas del crimen, a las características propias o de la víctima y al valor de la vida; el JVM (juicios de valor moral) más mencionado en el pasado fue que la acción sería incorrecta, por las consecuencias negativas; en el presente todos juzgaron como incorrecto el homicidio cometido, debido a las consecuencias negativas, al valor atribuido a la vida y a motivos religiosos. Esperamos que esas discusiones posibiliten mayor comprensión del sujeto homicida, para que principios universales, como el respeto a la vida, se puedan considerar y enseñar.

Palabras clave: moral, transgresión, homicidio.

Vários são os fatos que podem expressar um estado de violência, como as guerras, o homicídio, a opressão, as agressões físicas ou psicológicas, a destruição ambiental, a tortura, dentre outros. Alguns autores (Velho, 1996; Zaluar, 1996) defendem a importância de se estudar o tema da violência como uma boa oportunidade para analisar não

1 Trabalho baseado na dissertação de mestrado intitulada "Moralidade e homicídio: Um estudo sobre a motivação e a ação do transgressor", da primeira autora, sob orientação da segunda, defendida e aprovada em 2004 no Programa de Pós-graduação em Psicologia da Universidade Federal do Espírito Santo. As autoras agradecem ao apoio financeiro da CAPES e a todos aqueles que participaram da pesquisa.

2 Endereço para correspondência:

Luciana Souza Borges. Universidade Federal do Espírito Santo. Programa de Pós-graduação em Psicologia. Av. Fernando Ferrari, 514. CEP 29.075-

910. Vitória-ES, Brasil..E-mail: lu.sb@terra.com.br somente a sociedade, mas também a vida social. Explicam que o sistema de interações sociais é marcado pela heterogeneidade e, portanto, em constante potencial de conflito. Os autores também consideram que o crescimento trazido pela modernidade às grandes cidades afetou, sobretudo, o sistema ético das relações sociais, principalmente no que diz respeito às noções de reciprocidade, pois ideologias individualistas fortaleceram-se crescentemente.

Wieviorka (1997) discute um novo paradigma da violência, pela necessidade de contextualizá-la sob prisma dos acontecimentos sociais. Nessa medida, cada época histórica caracteriza-se por um estado de violência específico. Segundo Michaud (1989), a criminalidade reúne, contemporaneamente, a maior parte das discussões sobre a violência e será por esse panorama que visualizaremos sua ocorrência no Brasil, onde ela permeia as relações dos atores sociais, diante 
de uma pluralidade de situações econômicas, políticas e culturais. Dornelles (1988) refere-se à criminalidade brasileira como complexa e caracteriza-a como um "mosaico" (p. 62), em que se incluem, além do crime convencional (representado por sujeitos condenados e presos), as chamadas cifras negras da delinquência (representadas por aqueles que delinquem, mas permanecem impunes) e o crime do colarinho branco, cujos autores têm alto poder aquisitivo.

Zaluar (1996) afirma que o Brasil se encontra num ritmo avassalador da criminalidade, caracterizada por propósitos individualistas de enriquecimento rápido e de vingança interpessoal, reforçando mais uma vez a crise de valores em nosso país, muito mais do que a econômica. Adorno (1998) acrescenta às causas atuais da criminalidade a inadequação dos controles sociais, ou seja, a falha, segundo ele, está na esfera da moralidade. Diante de uma situação de anomia social, as violações das normas sociais deixam de ser punidas $\mathrm{e}$, consequentemente, tornam-se sistemáticas.

Zaluar (1996) diz ainda que é em meio a essa confusa rede social, na qual deparamos cada vez mais com a fragilidade das regras sociais e morais, que o sujeito deixa de levar o outro em consideração e comete uma ação transgressora. É nesse campo que se insere o homicídio, pois um dos direitos fundamentais, o direito à vida, fica fragilmente constituído nas teias sociais, resultando nos altos índices de assassinatos. Tratamos aqui de sujeitos cuja conduta se encaixa no artigo 121 do Código Penal Brasileiro (CPB) (Código Penal, 1997), que trata dos crimes dolosos contra a vida, tentados ou consumados. Esclarecemos que doloso é o crime praticado por aquele que deseja, espontaneamente, cometê-lo ou assume o risco de provocar o resultado ilícito.

Pesquisas (Beato Filho e cols., 2001; Cordeiro \& Donalisio, 2001; Macedo, Paim, Silva, \& Costa, 2001) indicam um súbito aumento do número de homicídios no Brasil, a partir dos anos de 1980, a maioria cometida por adultos jovens do sexo masculino. Os autores dizem ser esse crime um fenômeno social relacionado ao espaço urbano, especificamente em suas periferias, e que traduz uma violência manifestada no âmbito das relações interpessoais. Sobre serem homens os mais envolvidos como vítimas e agressores nesse tipo de violência, Sarti (2003) nos chama a atenção para o fato de que, nas classes economicamente desprivilegiadas, os espaços não são ocupados da mesma forma por homens e mulheres. Assim, o fato de ficar mais restrita aos espaços privados, em seu processo de socialização, traduz-se como fator de proteção para a mulher contra as mortes violentas, o que, por sua vez, aumenta os riscos para os homens.

Outros estudos (Centro Internacional de Investigação e Informação para a Paz, 2002; Mello Jorge, Gawryszewski, \& Latorre, 1997) constataram que o Brasil, juntamente com a Colômbia, México, Porto Rico e Venezuela, revela números assustadores de homicídios cometidos com dolo. Duas importantes questões foram destacadas nesse caso: a primeira diz respeito à relevância do uso de armas de fogo entre as mortes por causas externas; a segunda trata o cenário urbano como um local mais vulnerável à violência, tendo em vista as altas concentrações populacionais, as desigualdades sociais e as dificuldades nas inter-relações. A região da Grande Vitória-ES, especificamente, é apontada nessas análises como uma das localidades com mais elevada taxa de delitos dessa ordem. Zanotelli (2003) indica alguns dados referentes ao ano de 2001, a partir dos registros da Polícia Militar local: 8.230 registros de crimes contra a vida para uma população estimada em 1,3 milhões de habitantes, o que equivale a dizer que foram 615 casos por 100.000 habitantes, situação dimensionada pelo autor como sendo de calamidade pública.

Buscamos, então, circunscrever o tema estudado ao campo específico da Psicologia da Moralidade, pois aqueles que cometem um homicídio violam uma regra de convívio social e um fundamento de valor moral. Nessa perspectiva, o homicídio é um atentado contra o valor culturalmente elevado ao topo da pirâmide axiológica pela sociedade contemporânea, tanto sob o aspecto social, quanto sob o prisma moral, que é o valor da vida. Afirma La Taille (2002b) que, no caso da regra de não matar, a moral passa a ser considerada uma questão de dever pautada pelo princípio geral universalizado - o respeito à vida. Chamou-nos a atenção, então, o fato de algumas pessoas, em determinado momento de suas vidas, não serem capazes de agir segundo a regra moral de não matar, que diz respeito ao princípio geral do direito à vida.

Para Piaget (1932/1994), o desenvolvimento moral segue uma evolução que transita da moral heterônoma à autônoma. O estágio da heteronomia é caracterizado por relações de coação entre os sujeitos, pelas quais os mais jovens cumprem ordens e obedecem à autoridade dos mais velhos, o que enseja um respeito unilateral. A motivação para essa obediência teria suas raízes em dois tipos de sentimentos: o medo dirigido pela criança a essa figura de autoridade, pelo temor ao castigo, e também o medo de perder o amor desse sujeito.

Será, no entanto, pelas relações de cooperação que trocam entre si e pelo respeito mútuo que apresentam nessas interações sociais, que as crianças começarão a perceber o adulto como um semelhante, e não um superior a elas. Assim, as relações de coação cedem lugar às de cooperação e, consequentemente, o respeito unilateral vai dando lugar ao respeito mútuo, pelo qual passamos ao estágio da autonomia. Como assinala Piaget (1932/1994), os mais novos passam a apreciar o valor das regras que os mais velhos lhes propõem, não simplesmente obedecendo irrestritamente. Espera-se, assim, que se respeitem de forma simétrica e passem a interagir no âmbito social com parâmetros de igualdade. $\mathrm{O}$ sentimento que está na base desse estágio de autonomia passa a ser o medo moral de ser diminuído aos olhos do outro, daquele a quem os mais novos respeitam.

Portanto, Piaget (1932/1994) ensina que a moralidade envolve um conjunto de regras que existe devido à necessidade de convivência interpessoal. Assim, um indivíduo que 
se desenvolve moralmente, ou seja, que constrói sua autonomia, será capaz de alcançar um convívio social adequado com pares, para os quais as regras deverão fazer sentido. Será na convivência cotidiana, portanto, que as mensagens e os valores serão transmitidos constantemente, mesmo sem intenção. Assim, quando tratamos da moralidade, o processo de socialização tem fundamental valor na teoria piagetiana, pois é por meio das relações sociais vivenciadas que chegaremos a um sujeito autônomo.

Assim, as interações sociais são valorizadas por Piaget pela via da moral e é nesse sentido que influenciam o desenvolvimento dos sujeitos (La Taille, 1992). De acordo com este autor, o resultado esperado de um desenvolvimento moral que segue seu curso é a construção de um sujeito autônomo, ou seja, um sujeito que vivencia em suas relações sociais parâmetros de reciprocidade, que lhe permitam uma convivência de respeito mútuo com os seus pares, para que siga valores e regras em comum. Assim, tratar de desenvolvimento moral é tratar do desenvolvimento de crenças, valores e idéias dos indivíduos acerca do certo e do errado ou, em outras palavras, de seus juízos.

Contudo, dada a vastidão do campo de estudo da moralidade, abrem-se diversos caminhos pelos quais prosseguir na discussão teórica. Interessa-nos, no entanto, estudá-la a partir de discussões que tratem especificamente de temas atinentes à humilhação, devido à sua contribuição para a análise dos dados. La Taille (2002a) aborda a humilhação como um tipo de violência, pela qual podemos nos sentir rebaixados e inferiorizados perante o outro sem, contudo, necessariamente concordar com a imagem negativa sobre nós imposta. Assim, apesar de o outro fazer um juízo negativo de mim, eu não concordo com esse juízo, pois o juízo que faço de mim mesmo é diferente e eu não o modifico diante do juízo de outrem.

Para que haja um sentimento de rebaixamento, experimentado pela pessoa que se sente humilhada, é necessária a condição de que algum tipo de violência lhe seja dirigida. Portanto, "se alguém é insultado, surrado, obrigado a rastejar etc., fala-se em humilhação" (La Taille, 2002a, p. 94). Para Harkot-de-La-Taille (1999), é no próprio rebaixamento moral, traço específico da humilhação, que poderemos encontrar a ação violenta, na medida em que representa uma forma de manipulação da vítima. Assim, humilhar alguém seria, para a autora, uma maneira especialmente violenta de destruir a boa imagem daquele que está sendo humilhado.

Alencar e La Taille (2007) consideram também a noção do respeito, ou seja, a necessidade de reconhecer os direitos do outro, de fundamental importância para a abordagem do tema da humilhação. Nesse sentido, La Taille (2009) acrescenta que a humilhação fere um direito absoluto do ser humano, o da dignidade, pelo uso da coerção física ou psicológica para constranger alguém. Como consequência, a humilhação pode destruir o respeito que cada um possa ter por si mesmo, prejudicando, assim, a possibilidade de construção do respeito entre as pessoas e, em última instância, influenciando negativamente as relações humanas (Alencar \& La Taille, 2007).

La Taille (2002a) considera, ainda, várias formas de humilhação, que diferem entre si pelo grau de reciprocidade entre agressor e vítima, pelo período de duração que a ação violenta incide sobre a vítima e também pelo nível de gravidade com que atinge pontos centrais de sua personalidade. Ademais, Alencar e La Taille (2007) alertam para o fato de ser muito tênue o limite entre uma ação violenta leve e outra com a qual não conseguimos lidar, podendo ultrapassar a tolerância própria de cada um para esse tipo de situação. Nesse caso, pode a vítima, entre outras possibilidades, tentar fingir não se sentir humilhada, esquivar-se de situações sociais importantes, ou ainda transformar-se em agressor. Ades (1999) acrescenta que as reações que frequentemente acompanham aquele que sofre uma humilhação são "a raiva e o desejo de revidar, dentro ou fora de um código de honra” (p. 44). Em outras palavras, a violência do ato de humilhar poderá provocar uma atitude também violenta como reação daquele que se sente humilhado, como observaram Borges e Alencar (2006) em estudo sobre as motivações de homens que cometeram homicídio.

Outro ponto importante, segundo La Taille (2002a), é a possibilidade de ocorrerem reações às situações de humilhação que objetivem a defesa da própria honra. Diz o autor que a honra de alguém é em geral agredida por insultos e críticas e, nesses casos, se o insultado não reagir aos insultos, não a estará defendendo. Tal situação está ligada, segundo o autor, a muitos homicídios relacionados à defesa da própria honra por parte dos transgressores, o que representaria uma ação desprovida do sentido moral, na medida em que as regras não estariam sendo respeitadas. Harkot-de-La-Taille e La Taille (2004) apontam a complexidade do sentimento de honra ao explicarem que "resume um estado de alma vinculado às crenças mais profundas do sujeito sobre si mesmo, a ponto de este não o diferenciar de sua pessoa: honra ferida significa pessoa ferida" (p. 79). Os autores acrescentam o fato de esse sentimento ser construído por cada um de nós, dentro dos grupos aos quais pertencemos e mediante as trocas sociais, simbólicas e afetivas que vivenciamos.

Além disso, sabemos que a honra protege o respeito do sujeito por si mesmo e, assim, é como se colocasse uma proteção ao seu redor, para que outros não destruam o sentimento que tem de sua própria dignidade (La Taille, 2002a). Mereceu atenção especial por parte do autor o fato de a honra só fazer sentido quando inserida numa dimensão pública dos acontecimentos. Dessa forma, discutir o valor da honra remete-nos, em parte, ao campo do público, ou seja, ao campo daquilo que possa ser visto por outras pessoas. Por esse conceito, para conseguirmos ser honrados é preciso fazer coincidir o juízo que temos de nós mesmos com aquele que a sociedade possui de nós.

La Taille (1997) considera, portanto, que não podemos viver à margem de opinião alheia a nosso respeito, razão pela qual o ofendido poderia agir em defesa de sua honra. Nesse 
caso, La Taille (2002a) ressalta dois aspectos da honra: "pela honra" e "com honra" (p. 155). Geralmente, em uma ação "com honra" as regras são respeitadas e esse valor se vincula a virtudes como justiça, fidelidade e respeito à vida. Contrariamente, agir "pela honra" representaria uma perda do sentido moral da ação. Por exemplo: um sujeito comete homicídio por sofrer agressão física e entender que, se não matar seu agressor, pode ser desvalorizado como homem. Nesse caso, agiu pela honra, sem motivação moral. Assim, explica o autor, a conduta de um homicida não é virtuosa, pois não agiu "com honra" e revela uma ação moralmente nula de virtude. Agir "com honra", portanto, eleva o sujeito a uma condição em que passa a ser moralmente virtuoso. Por outro lado, o agir "pela honra" é o que faz um sujeito que atua de forma desonrosa, não moral.

Por fim, tendo em vista que os juízos estudados nesta pesquisa dizem respeito a homicídios que ocorreram há alguns anos, não pudemos investigar diretamente o contexto relacionado ao crime, cabendo-nos então estudar as representações que há hoje dessa realidade. Para tanto, trabalhamos com a análise dos juízos dos participantes em relação à sua ação criminosa e investigamos os juízos dos participantes por duas vias distintas, a do "juízo de representação da realidade" (JRR) e a do "juízo de valor moral" (JVM). Ao tratar o JRR da ação, buscamos saber se os participantes cometeriam novamente aquele homicídio, ao passo que no JVM da ação centramo-nos na avaliação dos sujeitos sobre sua ação transgressora. Assim, aferimos em que medida a ação transgressora está vinculada à moralidade dos sujeitos estudados.

A proposta deste estudo, portanto, foi investigar a representação atual de sujeitos homicidas a respeito do crime propriamente dito (ação), tanto à época do homicídio (passado) quanto no momento atual (presente), por meio do JRR e do JVM. Assim, caracterizamos a atual compreensão dessa realidade transgressora vivida pelo sujeito, a partir de seu próprio ponto de vista, avaliando se o seu JRR e o seu JVM diferem quando tratamos do passado e do presente. Avaliaremos, assim, se essa diferença temporal interferirá nesses dois tipos de juízos, quando investigamos a ação criminosa.

\section{Método}

\section{Participantes}

Compusemos a amostra com 20 homens, entre 30 e 49 anos de idade, que, na ocasião da coleta de dados, cumpriam pena em regime de liberdade condicional na Vara de Execuções Penais (VEP) de Vitória-ES por terem sido condenados pelo crime de homicídio doloso.

\section{Instrumentos e Procedimentos}

Utilizamos uma entrevista semiestruturada, a partir dos fundamentos do método clínico, originalmente proposto por Piaget (1932/1994), em sua forma puramente verbal (Delval, 2002). Interrogamos individualmente os participantes acerca do JRR e do JVM da ação do homicídio, de acordo com o seguinte roteiro de questões abertas: (a) (JRR - passado) Naquela época, quando pensava sobre o homicídio que cometeu, achava que, em circunstâncias parecidas, o cometeria novamente? Por quê?; (b) (JVM - passado) Naquela época, como julgou o homicídio que cometeu? Por quê?; (c) (JRR - presente) Hoje, quando pensa sobre o homicídio que cometeu, acha que, em circunstâncias parecidas, o cometeria novamente? Por quê?; (d) (JVM - presente) Hoje, como julga o homicídio que cometeu? Por quê?

Organizamos as questões, investigando primeiramente o passado e a seguir o presente, pois pretendíamos comparar os dois períodos temporais e analisar possíveis diferenças nessas respostas, em termos de desenvolvimento moral, sobre a ação propriamente dita. Priorizamos a análise qualitativa dos resultados, e contamos com a colaboração de uma juíza independente (Delval, 2002) na fase de categorização dos dados, como forma de garantir maior validação das categorias a serem definidas. Obtivemos um índice de concordância próximo a 98\% nesse processo final e, por fim, aplicamos o programa estatístico "SPSS for Windows" (1999) para análise dos dados, apresentados a seguir.

Quanto aos cuidados éticos, cumpre informarmos que a presente pesquisa, cujos resultados apresentamos a seguir, foi autorizada pelo Comitê de Ética em Pesquisa da Universidade Federal do Espírito Santo. Os nomes de todos os participantes são fictícios.

\section{Resultados}

Sobre o juízo de representação da realidade (JRR) da ação transgressora no passado, os 20 participantes ofereceram 33 respostas, agrupadas nas nove justificativas descritas na Tabela 1.

Constatamos que a maioria (22) das respostas dos participantes indica que naquela época matariam de novo e justificam essa forma de pensar, principalmente, em razão de 'Outras justificativas' (6), 'Por causa da humilhação por que passaram' (4) e 'Por causa do sentimento que vivenciaram' (4). No primeiro caso, são exemplos de justificativas englobadas sob essa categoria 'Porque não conhecia alternativa para se defender de uma agressão física', 'Porque estava alcoolizado' e 'Porque tudo era motivo suficiente para cometer um homicídio'. 
Tabela 1

Juízo de representação da realidade (JRR) da ação de cometer novamente o homicídio no passado: distribuição das respostas e das justificativas dos participantes

\begin{tabular}{|c|c|c|c|}
\hline \multirow{2}{*}{ Justificativas } & \multicolumn{2}{|c|}{ Faria de novo } & \multirow{2}{*}{ Total de justificativas } \\
\hline & Não & Sim & \\
\hline 1. Por causa das consequências (negativas ou positivas) & $5(45,4 \%)$ & $1(4,5 \%)$ & $6(18,2 \%)$ \\
\hline 2. Por causa de outras justificativas & - & $6(27,3 \%)$ & $6(18,2 \%)$ \\
\hline 3. Por causa de características próprias ou da vítima & $2(18,2 \%)$ & $3(13,6 \%)$ & $5(15,1 \%)$ \\
\hline 4. Por causa da humilhação por que passou & - & $4(18,2 \%)$ & $4(12,1 \%)$ \\
\hline 5. Por causa do sentimento que vivenciou & - & $4(18,2 \%)$ & $4(12,1 \%)$ \\
\hline 6. Por causa do valor da vida & $3(27,3 \%)$ & - & $3(9,0 \%)$ \\
\hline 7. Por causa da agressão física que sofreu & - & $2(9,1 \%)$ & $2(6,0 \%)$ \\
\hline 8. Porque precisava defender a própria vida ou de familiares & - & $2(9,1 \%)$ & $2(6,0 \%)$ \\
\hline 9. Não justificou & $1(9,1 \%$ & - & $1(3,0 \%)$ \\
\hline Total de respostas & $11(33,3 \%)$ & $22(66,7 \%)$ & 33 \\
\hline
\end{tabular}

As situações de humilhação, por sua vez, estiveram relacionadas a agressões físicas sofridas pelo transgressor antes do homicídio ou a outras circunstâncias que não envolviam agressão, mas que o fizeram sentir-se humilhado, como no exemplo que segue (utilizamos, no início de cada citação, entre parênteses, o nome fictício e a idade do entrevistado, com destaque para a sua fala):

O que passou pela sua cabeça, naquela época, quando você pensava no crime? Achava que se aquela cena tivesse se repetido, você o teria matado novamente? Acho que sim, porque mesmo depois dele morto, eu tinha muita revolta. Eu não me conformava de estar na cadeia e isso foi dificil para mim. Por quê? Isso não está dentro de mim, no meu jeito de viver. Eu sempre fui da roça, não era um cara de barulho assim. Mas você me disse que tinha muita revolta, mesmo naquela época, depois que você o matou. E se tivesse acontecido de novo, você teria matado de novo? Com certeza, naquela época sim. Por quê? Porque eu senti muita raiva dele, por causa da traição. E porque ele tinha que ter pensado antes de me roubar, mas tinha que ter pensado duas vezes antes de me contar que tinha roubado porque me senti muito humilhado com isso. Inclusive lá na cadeia aconteceram algumas coisas, lata que caía e luz que apagava sozinha, e um cara de dentro da cela pediu para queimar vela para o rapaz que eu tinha matado, porque ele estaria me perturbando. Eu respondia que se ele aparecesse de novo na minha frente, eu o mataria e, na época, mataria mesmo. (Fábio, 36 anos)

O relato de Fábio ilustra também as situações em que os entrevistados justificaram que cometeriam novamente o homicídio 'Por causa do sentimento que vivenciaram'. Geralmente, emergiram por parte dos sujeitos sentimentos de raiva, ódio e medo, sempre direcionados à vítima.

Quanto ao juízo de representação da realidade (JRR) da ação transgressora no presente, encontramos 41 respostas, agrupadas nas seis justificativas apresentadas na Tabela 2:

Tabela 2

Juízo de representação da realidade (JRR) da ação de cometer novamente o homicídio no presente: distribuição das respostas e das justificativas dos participantes

\begin{tabular}{|c|c|c|c|c|}
\hline \multirow{2}{*}{ Justificativas } & \multicolumn{3}{|c|}{ Faria de novo } & \multirow{2}{*}{$\begin{array}{c}\text { Total de } \\
\text { justificativas }\end{array}$} \\
\hline & Não & Sim & Não sabe & \\
\hline 1. Por causa das consequências (negativas ou positivas) & $19(55,9 \%)$ & $2(40,0 \%)$ & - & $21(51,2 \%)$ \\
\hline 2. Por causa de características próprias ou da vítima & $6(17,6 \%)$ & $1(20,0 \%)$ & $1(50 \%)$ & $8(19,5 \%)$ \\
\hline 3. Por causa do valor da vida & $4(11,8 \%)$ & - & - & $4(9,7 \%)$ \\
\hline 4. Por causa de outras justificativas & $2(5,9 \%)$ & $1(20,0 \%)$ & $1(50 \%)$ & $4(9,7 \%)$ \\
\hline 5. Por causa de motivos religiosos & $3(8,8 \%)$ & - & - & $3(7,3 \%$ \\
\hline 6. Por causa da humilhação por que passou & - & $1(20,0 \%)$ & - & $1(2,4 \%)$ \\
\hline Total de respostas & $34(82,9 \%)$ & $5(12,2 \%)$ & $2(4,9 \%)$ & 41 \\
\hline
\end{tabular}


Observamos que a maioria das respostas dos entrevistados (34) refere-se ao fato de acharem que hoje não cometeriam novamente esse crime. As justificativas que se destacaram foram 'Por causa das consequências negativas' (19), 'Por causa de características próprias ou da vítima' (6) e 'Por causa do valor da vida' (4). O caso a seguir ilustra a primeira situação:

O que passa pela sua cabeça hoje, quando você pensa no homicídio que mandou alguém fazer? Você acha que, se tudo ocorresse da mesma forma hoje, você mandaria matar novamente a moça? Hoje eu pensaria duas vezes antes de mandar fazer isso. Por quê? Porque não aguento esse tratamento de cadeia, não! Ser tratado igual cachorro de rua. Foi o que aconteceu com você na cadeia? Os policiais tratam a gente muito mal (...). Por isso hoje em dia, antes de fazer qualquer coisa, eu penso bem, para não voltar para aquele lugar. Então hoje você não a mandaria matar? Não, ela poderia me jogar maconha na cara, uma, duas, dez vezes, quantas vezes ela quisesse que eu não faria mais isso. O que você perdeu ao ir para a cadeia? Agora há pouco você me disse que estragou sua juventude por causa desse crime. Quando eu fui preso minha filha tinha três meses de nascida e após a prisão eu e a mãe dela nos separamos. Então fiquei esse tempo todo de prisão sem ver a minha filha. Hoje ela já não me conhece, se eu tentar pegá-la no colo ela não quer vir comigo. Somente isso para mim já foi uma perda total. E eu perdi minha juventude na cadeia. A sua separação de sua esposa foi por causa da sua prisão? Foi. Ela mora com outra pessoa e teve outro filho. (Fernando, 30 anos)

A segunda situação ('Por causa de características próprias ou da vítima') está relacionada a maneiras de ser tanto do agressor quanto da vítima, específicas de um determinado momento de suas vidas, como, por exemplo: 'Hoje não cometeria de novo o homicídio, dadas as mesmas circunstâncias, porque, ao ficar mais velho, se aprendem muitas coisas, se ganha experiência de vida' ou ainda 'Hoje não cometeria de novo o homicídio, dadas as mesmas circunstâncias, porque as vítimas eram muito jovens'. A última situação ('Por causa do valor da vida') também foi destacada face à sua importância na discussão dos dados.

Quando comparamos os juízos de representação da realidade (JRR) da ação transgressora no passado e no presen$t e$, constatamos que a resposta mais mencionada foi inversa para cada momento estudado: os participantes acham que matariam novamente no passado, ao passo que hoje teriam outra atitude, que não levasse ao crime. As justificativas para o passado dão ênfase a situações de humilhação vividas e a fortes sentimentos negativos vivenciados, enquanto que para o momento atual referem-se, principalmente, às consequências negativas que a ação criminosa lhes trouxe.

Sobre o juízo de valor moral (JVM) da ação transgressora no passado, os entrevistados deram um total de 40 respostas, agrupadas nas seis justificativas que apresentamos na Tabela 3:

Tabela 3

Juizo de valor moral (JVM) da ação de cometer o homicídio no passado: distribuição das respostas e das justificativas dos participantes

\begin{tabular}{lccccc}
\hline \multirow{2}{*}{ Justificativas } & \multicolumn{5}{c}{ Como julgou o homicídio } \\
\cline { 2 - 6 } & Errado & Correto & $\begin{array}{c}\text { Errado e } \\
\text { correto }\end{array}$ & Não sabe & $\begin{array}{c}\text { Total de } \\
\text { justificativas }\end{array}$ \\
\hline 1. Por causa das consequências (negativas ou positivas) & $13(68,4 \%)$ & $1(7,7 \%)$ & $2(100 \%)$ & - & $16(40,0 \%)$ \\
2. Por causa das características próprias ou da vítima & $2(10,5 \%)$ & $3(23,1 \%)$ & - & $3(50,0 \%)$ & $8(20,0 \%)$ \\
3. Por causa de outras justificativas & $1(5,3 \%)$ & $3(23,1 \%)$ & - & $3(50,0 \%)$ & $7(17,5 \%)$ \\
4. Por causa da humilhação por que passou & - & $4(30,7 \%)$ & - & - & $4(10,0 \%)$ \\
5. Por causa de motivos religiosos & $2(10,5 \%)$ & $1(7,7 \%)$ & - & - & $3(7,5 \%)$ \\
6. Porque precisava defender a própria vida ou de & $1(5,3 \%)$ & $1(7,7 \%)$ & - & - & $2(5,0 \%)$ \\
familiares & $19(47,5 \%)$ & $13(32,5 \%)$ & $2(5,0 \%)$ & $6(15,0 \%)$ & 40 \\
Total de sujeitos & & & & &
\end{tabular}

Percebemos que as respostas se dividem, principalmente, entre achar que julgavam o homicídio como 'Errado' (19) e achar que o julgavam como 'Correto' (13). No primeiro caso, justificam, majoritariamente, 'Por causa das consequências (negativas)' (13), que poderiam se referir ao transgressor, à sua família ou ainda à família da vítima. Por exemplo, Pedro, que matou um padre, julgou errada sua ação transgressora porque, sendo a vítima quem era, achou que pudesse ser morto ou nunca mais sair da prisão. 
No segundo caso, para os participantes que acham que julgavam o homicídio como 'Correto', as justificativas que se destacam são 'Por causa da humilhação por que passaram' (4) e 'Por causa das características próprias ou da vítima' (3), como ilustramos em seguida:

Por causa da humilhação por que passaram

E, naquela época, logo depois de matá-lo, você achou que tinha feito a coisa certa? Eu achei que foi certo! Por quê? Porque o cara só ficava abusando de mim, no meio da rua. O fazendeiro e os peões não me podiam ver que falavam: "ah, fulano te bateu e você não fez nada com ele?". E eu respondia, "pode ficar quieto porque eu vou matá-lo qualquer dia". E deixei passar um ano ainda. Por que esperou esse tempo? Porque minha mulher estava com filho muito pequeno, que nem andava ainda, e eu quis esperar até ele andar para que ela pudesse trabalhar para cuidar dele, se eu fosse preso ou morresse. Quando meu filho começou a andar eu falei: "você trate de ir embora porque hoje venceu o dia de eu matar aquele cara e não vai ter escapatória para ele". Ela chorou, mas eu a levei para a casa do pai dela. Após 30 dias eu o matei. E ainda falei: "se eu morrer alguém vem te avisar, se eu matar eu mesmo venho para te avisar" Depois do crime, eu ainda passei na fazenda para avisá-la de que eu tinha matado. (Joaquim, 36 anos)

\section{Por causa de características próprias ou da vítima}

Naquela época, você achou certo o crime que tinha cometido? Achei. Por quê? Porque eu achei certo ela ter morrido? Porque ela merecia, merecia mesmo. (...) Ela era malvista no bairro porque pegava as coisas, roubava para pegar drogas. Se não fosse eu que fizesse isso, seria outra pessoa. Ela era viciada e enjoada. (Fernando 30 anos)

Quanto ao juízo de valor moral (JVM) da ação transgressora no presente, obtivemos 42 respostas, distribuídas entre cinco justificativas: 'Por causa das consequências negativas' (17), 'Por causa do valor da vida' (9), 'Por causa de motivos religiosos' (7), 'Por causa das características próprias ou de vítima' (5) e 'Outras justificativas' (4). Todos os entrevistados, no entanto, responderam que hoje julgam errada a ação transgressora cometida, como veremos em seguida por meio de exemplos das três justificativas mais incidentes:

Por causa das consequências negativas e Por causa de motivos religiosos

Você hoje acha certo o homicídio que cometeu? Não. Por quê? Porque a gente não pode dar outra. Quem deu a vida para nós é Um só e nós não sabemos dar e nem temos o direito de tirar. E também porque já passei por muito sofrimento depois desse crime, tomei muito prejuízo com isso. Como diz o ditado, "o crime não compensa” (...). Por que não? (...) Porque por pior que seja a situação que estamos passando é melhor deixar para lá, porque a consequência vai ser pior. Quando a pessoa nunca passou por isso, principalmente um cara mais novo, que não está sabendo o que é a vida, como aconteceu no meu caso. Eu não sabia o que aconteceria depois do crime cometido, não sabia da situação que viria para mim depois. Então se a pessoa não sabe o que está por vir, acha até que está fazendo bonito, mas depois de certa idade a gente começa a conviver com coisas mais sérias, como na minha situação e na de tantos outros. Se aprontar de novo, então é porque não vai aprender nunca. Pelo que passou na prisão? $E$, porque ele agora já tem a experiência e sabe o que acontece para saber que não vale a pena. Por isso é que não compensa. (Paulo, 41 anos)

Por causa do valor da vida

Você acha certo o homicídio que cometeu? O homicídio é o seguinte, é tirar a vida de uma pessoa, e isso não pode ser certo. Por que não? Eu não acho certo porque ninguém tem o direito de tirar a vida de ninguém. E a pessoa estando alcoolizada ou normal, não importa, ela está tirando a vida de um irmão dele. Mesmo estando alcoolizado, como você estava, não acha que tenha feito o que é certo? Não, no outro dia quando fui pensar eu vi que tinha feito uma coisa muito errada, mas não dava para voltar atrás. Para mim estava tudo normal, e quando sai dali, ainda fui para outro bar, beber mais ainda. Eu não sabia o que estava fazendo mais. No outro bar eu continuei bebendo e foi quando a polícia veio e me prendeu. (Edgar, 43 anos)

Ao comparar os juízos de valor moral (JVM) da ação transgressora no passado e no presente, verificamos que, quando os sujeitos são instados a pensar sobre a época do delito, as respostas se dividem entre os que julgavam errada sua ação por causa das consequências negativas e os que a julgavam correta por terem se sentido humilhados ou devido às suas próprias características ou às das vítimas. Mas hoje em dia todos os entrevistados julgam como errado o crime cometido e justificam essa avaliação, principalmente, com base nas consequências ruins que esse fato lhes causou.

\section{Discussão}

Apesar de todos os participantes terem avaliado o homicídio como algo errado (JVM) no presente, algumas 
respostas apontam para a possibilidade de reincidência nesse crime (JRR) ou mesmo para a dúvida quanto a cometê-lo ou não. O mesmo ocorre quando se volta no tempo. Embora a maioria tenha julgado a ação do homicídio como errada (JVM) no passado, grande parte das respostas aponta para o fato de que matariam outra vez na época (JRR), caso estivessem na mesma situação. Temos aqui um resultado importante, pois o simples fato de alguns entrevistados julgarem errada a ação homicida não garante a não-representação da sua realização, seja no presente seja no passado. Essa temática é de fundamental importância para os estudos no campo da moralidade, pois poderemos ter um juízo moral sobre determinada questão, o que não determinará que nossa ação venha a ser moral, necessariamente. Embora não tivéssemos investigado a ação propriamente dita, mas sua representação, os dados apontaram para a importância dessa relação entre juízo e ação.

Nesse sentido, consideramos relevante mencionar dois participantes, Edgar e Célio, que apresentaram dúvidas quanto a matar novamente ou não (JRR), hoje em dia, caso deparassem com a mesma situação que os levara ao delito. As justificativas que apresentaram são: Edgar - "Porque ninguém sabe o que uma pessoa alcoolizada é capaz de fazer"; Célio - "Porque em um momento como aquele - apanhar na cara - as reações do cérebro podem ser imprevisíveis". Ambos não permaneceram presos pelo crime que cometeram, dado que nos faz pensar sobre as consequências da impunidade sobre o JRR da ação criminosa, e também, em última instância, sobre a própria reincidência criminal (ação), tão comum em nossa sociedade. Esse exemplo corrobora, a nosso ver, a necessidade de pesquisas que priorizem a relação entre juízo e ação para sujeitos infratores diante de seus delitos cometidos.

É importante também notar que, no presente, os participantes parecem ter modificado tanto seu juízo de representação da realidade (JRR) quanto seu juízo de valor moral (JVM), quando pensam no homicídio que cometeram em outro momento de sua vida. Nesse sentido, se acham que cometeriam novamente o crime naquela época, deixam de pensar dessa forma nos dias de hoje (JRR), e, se há tanto os que podem julgar o delito como algo errado quanto os que podem julgá-lo como algo correto ao referir-se ao passado, agora todos participantes passam a considerar o crime cometido como uma ação errada (JVM). Dito de outra forma: os entrevistados hoje, em sua maioria, julgam como errado o homicídio em si e alegam que não o fariam de novo, primordialmente, por conta do quanto se sentiram prejudicados com suas consequências negativas.

Esse resultado nos remete à reflexão de que, não fossem desfavoráveis a eles tais consequências, os participantes poderiam apresentar para o presente o mesmo JRR e JVM que do passado, ou seja, a maioria responderia que atualmente mataria outra vez diante das mesmas circunstâncias e julgaria como correto o homicídio cometido. Concluímos que a mudança ocorrida na forma de pensar dos agressores parece ter sido determinada pelas consequências adversas sofridas após a transgressão, o que aponta para traços de heteronomia (Piaget, 1932/1994). Dessa forma, os entrevistados estariam lidando de determinada maneira com as regras sociais por medo de infringi-las e não porque compreendem seu sentido e sabem que seu cumprimento se deve ao fato de terem sido estabelecidas para o convívio social.

Chamamos a atenção para as justificativas relacionadas às situações de humilhação vividas pelos entrevistados, que aparecem quase que exclusivamente quando se referem ao tempo passado, seja no JRR seja no JVM da ação. Vejamos alguns exemplos sobre essas justificativas para o JRR da ação: "Porque se sentiu humilhado quando o amigo lhe contou que o havia roubado", "Porque a pessoa que sofre agressão física fica desonrada". Sobre o JVM da ação: "Porque a vítima ficava abusando dele no meio da rua", "Porque foi agredido dentro de sua própria casa". Nesse sentido, utilizam argumentos de humilhação aqueles que querem justificar o fato de que matariam de novo e também para argumentar sobre por que julgavam como correto o homicídio cometido, à época em que o crime se deu.

Assim, sempre que a justificativa "Por causa da humilhação por que passou" aparece para fundamentar as respostas de questões investigadas no passado, vemos que a humilhação vivida pelos transgressores, antes do crime cometido, os faz reagir cometendo o homicídio, ou seja, eles agem "pela honra", diante daquelas situações. Lembramos que, sendo a humilhação um tipo de violência caracterizada pelo rebaixamento moral da vítima (Harkot-de-La-Taille, 1999; La Taille, 2002a), poderá haver reações também violentas por parte desta para revidar o sentimento de humilhação (Ades, 1999; Borges \& Alencar, 2006). Na presente pesquisa, os participantes cometeram um crime de homicídio contra suas vítimas após sentirem-se humilhados por elas, ou seja, após eles mesmos terem sido vítimas dos insultos por parte delas.

Defender-se de insultos pode significar também a defesa da própria honra (La Taille, 2002a), evitando assim que o sentimento que o humilhado tem de sua própria dignidade, do respeito por si mesmo, seja destruído. Como ressaltamos (Harkot-de-La-Taille \& La Taille, 2004), a honra está vinculada a aspectos profundos da personalidade de cada um e, portanto, ter a honra ferida poderá ser o mesmo que a própria pessoa sentir-se ferida. Nesse caso, os entrevistados reagiram aos insultos para se proteger, mas agiram "em nome da honra", e não "com honra" (La Taille, 2002a), na medida em que não respeitaram a regra de "não matar", vinculada à virtude do "respeito à vida". Perdeu-se, portanto, o caráter moral e honroso na reação que os entrevistados tiveram ao fato de terem se sentido humilhados.

O último ponto de análise trata dos resultados pertinentes ao valor da vida e aos motivos religiosos mencionados tanto para o JRR quanto para o JVM. Alguns participantes utilizaram a justificativa "Por causa do valor da vida" para argumentar que não matariam de novo (JRR) nem no passado 
nem no presente, além de terem avaliado no presente como errado (JVM) o homicídio cometido. Notamos que o valor da vida, apesar de ter baixa incidência nos dados encontrados, não aparece somente para o JVM no passado. Conforme mencionamos (La Taille, 2002b), o valor da vida segue um princípio geral universalizado - "o respeito à vida" que, no caso de nossos participantes, não foi encontrado entre as justificativas de ninguém que tenha julgado como errado, no passado, o homicídio que cometeu.

Quanto à justificativa "Por causa de motivos religiosos", os entrevistados a apresentaram para explicar o fato de que não matariam novamente no presente e que julgaram como errado o crime cometido tanto no presente quanto no passado. Notamos que essa justificativa não aparece somente para o JRR no passado, ou seja, motivos religiosos não justificaram respostas relacionadas ao fato de que não cometeriam novamente o crime naquela época.

De maneira geral, percebemos que o valor da vida e os motivos religiosos ganharam maior destaque nas respostas que os entrevistados forneceram no presente. Tal resultado aponta para uma mudança da representação atual que os participantes possuem dos dois momentos de tempo investigados, embora, pela maior incidência de respostas, nos faça refletir especificamente sobre o JVM, no que se refere ao valor da vida, e acerca do JRR no caso dos motivos religiosos.

\section{Considerações finais}

Os resultados dessa pesquisa indicaram que o JRR mais citado pelos participantes no passado foi o de que cometeriam novamente o delito devido, principalmente, à humilhação sofrida ou ao sentimento negativo experienciado, ao passo que, no presente, afirmaram que não matariam de novo, devido às conseqüências negativas do crime, às suas características próprias ou às da vítima e ao valor da vida. Quanto ao JVM no passado, o mais mencionado foi o de que a ação seria errada pelas consequências negativas, enquanto no presente todos os entrevistados julgaram como errado o homicídio cometido, em vista das consequências negativas, ao valor atribuído à vida e a motivos religiosos.

De posse dos resultados obtidos em nossa pesquisa, finalizamos esta discussão com duas considerações que julgamos de fundamental importância. A primeira refere-se ao fato de que, sendo o homicídio um crime cometido quando o valor da vida é menosprezado ou ignorado, passar a julgar o delito cometido como algo errado por causa desse valor pode ter sido uma mudança advinda com o decorrer do tempo, na vida de alguns entrevistados. Ressaltamos, assim, a importância de pesquisas que averigúem circunstâncias e experiências de vida que poderiam influenciar os juízos dos infratores com relação ao delito cometido.

Importa também anotar que, embora não tenhamos investigado as orientações religiosas dos participantes, esse resultado nos fez pensar se haveria influência de aspectos religiosos sobre os juízos dos participantes e que tipo de influência seria essa. Lembramos que os participantes que alegaram motivos religiosos em suas justificativas deixaram claro que sua opção religiosa firmou-se apenas após a prisão, quando ainda estavam encarcerados. Eles estabelecem diferenças quanto à sua religiosidade, ao comparar a época do crime com o período atual, fato que está a exigir estudos que avaliem os possíveis efeitos dos aspectos religiosos sobre os juízos dos transgressores.

Esperamos, enfim, que as discussões a respeito deste estudo possibilitem maior compreensão do sujeito homicida, no que tange à ação transgressora e aos juízos que ele apresenta em face desse delito. Mesmo diante da constatação de aspectos que ainda necessitam de investigação, como a relação entre juízo e ação ou a influência de aspectos religiosos sobre os juízos dos participantes, conforme apontamos, acreditamos haver colaborado para a reflexão acerca do tema da violência, tão urgente em nosso cenário social. Fizemos isso com interesse voltado aos estudos do campo da moralidade, pois entendemos que o desenvolvimento dos juízos integra um processo mais amplo de formação moral, que abrange alguns princípios universais - como o respeito à vida -, os quais, apesar de suas diversidades, podem ser a todos ensinados por meio da educação moral.

\section{Referências}

Ades, L. (1999). Em nome da honra: Reações a uma situação de humilhação. Dissertação de mestrado não-publicada, Universidade de São Paulo, São Paulo.

Adorno, S. (1998). Conflitualidade e violência [Versão eletrônica]. Tempo Social, 10(1), 19-47. Recuperado em 10 julho 2004, de http://www.fflch.usp.br/sociologia/ temposocial/pdf/vol10n1/conflitualidade.pdf

Alencar, H. M., \& La Taille, Y. (2007). Humilhação: O desrespeito no rebaixamento moral [Versão eletrônica]. Arquivos Brasileiros de Psicologia, 59, 217-231. Recuperado em 20 outubro 2008, de http://pepsic.bvspsi.org.br/pdf/arbp/v59n2/v59n2a11.pdf

Beato Filho, C. C., Assunção, R. M., Silva, B. F. A., Marinho, F. C., Reis, I. A., \& Almeida, M. C. (2001). Conglomerados de homicídios e o tráfico de drogas em Belo Horizonte, Minas Gerais, Brasil, de 1995 a 1999 [Versão eletrônica]. Cadernos de Saúde Pública, 17, 1163-1171. Recuperado em 08 maio 2002, de http:// www.scielo.br/pdf/csp/v17n5/6324.pdf

Borges, L. S., \& Alencar, H. M. (2006). Moralidade e homicídio: Um estudo sobre a motivação do transgressor [Versão eletrônica]. Psicologia: Reflexão e Crítica, 19, 451-459. Recuperado em 02 fevereiro 2008, de http:// www.scielo.br/pdf/prc/v19n3/a14v19n3.pdf

Centro Internacional de Investigação e Informação para a Paz. (2002). O estado da paz e a evolução da violência: A situação da América Latina. Campinas: Ed. Unicamp. 
Código Penal. (1997). São Paulo: Ed. Revista dos Tribunais.

Cordeiro, R., \& Donalisio, M. R. C. (2001). Homicídios masculinos na região metropolitana de São Paulo entre 1979 e 1998: Uma abordagem pictórica [Versão eletrônica]. Cadernos de Saúde Pública, 17, 669-677. Recuperado em 08 maio 2002, de http://www.scielo.br/ $\mathrm{pdf} / \mathrm{csp} / \mathrm{v} 17 \mathrm{n3} / 4649 . \mathrm{pdf}$

Delval, J. (2002). Introdução à prática do método clínico: Descobrindo o pensamento das crianças (F. Murad, Trad.). Porto Alegre: Artmed.

Dornelles, J. R. W. (1988). O que é crime. São Paulo: Brasiliense.

Harkot-de-La-Taille, E. (1999). Ensaio semiótico sobre a vergonha. São Paulo: Humanitas.

Harkot-de-La-Taille, E., \& La Taille, Y. (2004). Construção ética e moral de si mesmo. In De Souza, M. T. C. C. (Org.), Os sentidos de construção: O si mesmo e o mundo (pp. 69-101). São Paulo: Casa do Psicólogo.

La Taille, Y. (1992). O lugar da interação social na concepção de Jean Piaget. In Y. La Taille, M. K. Oliveira, \& H. Dantas (Orgs.), Piaget, Vygotsky e Wallon: Teorias psicogenéticas em discussão (pp. 11-21). São Paulo: Summus editorial.

La Taille, Y. (1997). Para um estudo psicológico da honra. In L. Banks-Leite (Org.), Percursos piagetianos (pp. 225241). São Paulo: Cortez.

La Taille, Y. (2002a). Vergonha: A ferida moral. Petrópolis, RJ: Vozes.

La Taille, Y. (2002b). Notícias de uma guerra particular: Debate sobre vídeo. In I. M. C. Oliveira, G. A. Pavez, \& F. Schilling (Orgs.), Reflexões sobre justiça e violência: $O$ atendimento a familiares de vitimas de crimes fatais (pp. 227-244). São Paulo: Educ.

La Taille, Y. (2009). Formação ética, do tédio ao respeito de si. Porto Alegre: Artmed.

Macedo, A. C., Paim, J. S., Silva, L. M. V., \& Costa, M. C. N. (2001). Violência e desigualdade social: Mortalidade por homicídios e condições de vida em Salvador, Brasil [Versão eletrônica]. Revista de Saúde Pública, 35, 515522. Recuperado em 08 maio 2002, de http://www.scielo. br/pdf/rsp/v35n6/7063.pdf

Mello Jorge, M. H. P., Gawryszewski, V. P., \& Latorre, M. R. D. de O. (1997). Análise dos dados de mortalidade [Versão eletrônica]. Revista de Saúde Pública, 31 (Suppl. 4), 5-25. Recuperado em 10 julho 2004, de http://www. scielo.br/pdf/rsp/v31n4s0/3134.pdf

Michaud, Y. (1989). A violência (L. Garcia, Trad.). São Paulo: Ática.

Piaget, J. (1994). O juízo moral na criança (E. Leonardon, Trad., 2a ed). São Paulo: Summus. (Original publicado em 1932)

Sarti, C. A. (2003). A família como espelho: Um estudo sobre a moral dos pobres. São Paulo: Cortez.
SPSS for Windows. (1999). Statistical package for social sciences Base 10.0: Application Guide. Chicago, IL.

Velho, G. (1996). Violência, reciprocidade e desigualdade: Uma perspectiva antropológica. In G. Velho \& M. Alvito (Orgs.), Cidadania e violência (pp. 10-24). Rio de Janeiro: Ed. UFRJ/ Ed. FGV.

Wieviorka, M. (1997). O novo paradigma da violência. Tempo Social, 9(1), 5-41. Recuperado em 10 julho 2004, de http:/www.fflch.usp.br/sociologia/temposocial/pdf/ vol09n1/o\%20novo.pdf

Zaluar, A. (1996). Da revolta ao crime S. A. São Paulo: Moderna.

Zanotelli, C. L. (2003). O espaço da violência na grande Vitória: O caso dos homicídios. In T. Camacho (Org.), Ensaios sobre violência (pp. 237-260). Vitória: Ed. UFES.

Luciana Souza Borges é doutoranda em Psicologia pelo Programa de Pós-graduação em Psicologia da Universidade Federal do Espírito Santo, bolsista CNPq.

Heloisa Moulin de Alencar é Professora Adjunta do Departamento de Psicologia Social e do Desenvolvimento e do Programa de Pós-graduação em Psicologia da Universidade Federal do Espírito Santo, campus universitário de Goiabeiras.

Recebido: $15 / 05 / 2008$

$1^{a}$ revisão: $31 / 03 / 2009$

$2^{a}$ revisão: $28 / 05 / 2009$

Aceite final: 08/06/2009 